\title{
Implicaciones de los acuerdos del Fondo Monetario Internacional sobre la pobreza en Colombia ${ }^{1}$
}

\section{Implications of International Monetary Fund agreements on poverty in Colombia}

DOI: http://dx.doi.org/10.17981/econcuc.38.1.01

Julián Augusto Casas Herrera²

\begin{abstract}
Resumen
Este documento analiza las implicaciones de los acuerdos del Fondo Monetario Internacional (FMI) en la pobreza en Colombia. Se demuestra que, durante las intervenciones, el Fondo asoció la pobreza, únicamente, con insuficiencia de ingreso, de ahí que sus intervenciones no redujeron la incertidumbre de los pobres; y aunque los indicadores de pobreza tuvieron una mejora, se sostiene que las posibilidades y capacidades reales de los pobres no mejoraron. Para demostrarlo, se parte de una definición de pobreza y de los principios que fundamentan la razón de ser del organismo internacional objeto de estudio, así como de los aspectos que involucra la incertidumbre, como una arista que clarifica que las intervenciones del ente acrecentaron la pobreza al garantizar la rentabilidad del capital.
\end{abstract}

Palabras clave: acuerdos internacionales; pobreza; Fondo Monetario Internacional.

Recibido: 20/2/2017 Devuelto para revisión: 12/5/17 Aceptado: 27/5/2017.

\footnotetext{
${ }^{1}$ Artículo de revisión producto del trabajo del grupo de investigación Modelos de Desarrollo en América Latina, bajo la línea de investigación desigualdad económica y política social, presentado en la Universidad Pedagógica y Tecnológica de Colombia (UPTC).

${ }^{2}$ Magister en Ciencias Económicas de la Universidad Nacional. Colombia. Especialista en finanzas. Economista de la Universidad Pedagógica y Tecnológica de Colombia UTPC. Docente de la Escuela de Economía de la Universidad Pedagógica y Tecnológica de Colombia. Correo: julian.casas01@uptc.edu.co.
} 


\begin{abstract}
This paper analyzes the implications of International Monetary Fund (IMF) agreements on poverty in Colombia. It is shown that during the interventions the fund associated poverty only, with insufficient income, hence their interventions did not reduce the uncertainty of the poor; And although the poverty indicators improved, it is argued that the real possibilities and capacities of the poor did not improve. In order to demonstrate this, it is based on a definition of poverty and the principles underlying the raison d'être of the international organization under study, as well as the aspects that involve uncertainty, as an edge that clarifies that the interventions of the institution increased poverty to Guarantee the profitability of capital.
\end{abstract}

Key words: international agreements; poverty; International Monetary Fund.

\title{
Introducción
}

El Fondo Monetario Internacional (FMI) es un organismo de financiación internacional que justifica su existencia en el hecho de que los países enfrentan, con alguna frecuencia, crisis económicas internas, la mayoría de ellas por cesación de pagos; es decir, por restricción en la disponibilidad de divisas. Generalmente, este tipo de problemas acontece con mayor frecuencia en los países en vía de desarrollo. Tal entidad utiliza metodologías homogéneas para conducir su intervención en los distintos países donde lo hace, dado que parte de suponer que los problemas de cada país son de la misma naturaleza. 
Los países en vía de desarrollo, enfrentan en distinto grado situaciones de pobreza de sus habitantes, fenómeno que en la mayoría de ellos constituye el principal problema, al que tiene que enfrentarse los gobiernos de turno. Por esta razón, el FMI argumenta que sus modelos de intervención apuntan a reducir la pobreza en tales países, sin embargo se observan dos dificultades: la primera tiene que ver con que después de dichas intervenciones, la pobreza no se reduce de manera visible; la segunda se refiere a la definición de pobreza que el FMI utiliza para guiar sus intervenciones, pues este organismo la concibe como un problema de insuficiencia de renta, únicamente.

En este sentido, el enfoque que orienta la discusión cuestiona la manera de concebir la pobreza argumentando que es visiblemente reduccionista. De tal manera, que el proceso de revisión de conceptos de pobreza, encuentra que aún faltan elementos que hacen referencia a la dimensión humana. Uno de estos elementos faltantes en los distintos estudios y análisis sobre la pobreza, es la incertidumbre. Este es el elemento que se intenta incorporar en el concepto y análisis de la pobreza, para intentar examinar la incidencia de las intervenciones del FMI sobre la pobreza en Colombia. Lo descrito, permite analizar con rigor a partir de una definición de pobreza que involucra la incertidumbre, como una de las expresiones más palpables e irreductibles en cada ser humano intervienen visiblemente en las directrices del FMI, y por ende en el aumento o reducción de la pobreza en Colombia a partir de los acuerdos que firmó el país con la entidad.

En tal sentido, la incertidumbre adquiere importancia y es fundamental incluirla en la discusión y en el concepto de pobreza, porque hace presencia permanente en la mayoría de las situaciones de los agentes económicos guiados por la esencia humana. En consecuencia, no se dice que los conceptos de pobreza, propuestos anteriormente por varios autores, carezcan de todos los elementos que componen a la pobreza; sino que falta este elemento y, seguramente, hacen falta muchos más. En función de ello, este documento se aparta de los métodos tradicionales o reduccionistas de medición de la pobreza, puesto que si aún no se ha definido con precisión qué significa la pobreza, es razonable dudar sobre sus formas de medición.

Desde la perspectiva expuesta, se plantea que el enfoque se orienta en entender que la pobreza estaría (en algún sentido) asociada a una extinción paulatina del flujo de servicios regulares en las personas; y en consecuencia esto induce un aumento de la incertidumbre, 
que se refleja en la intensificación del sufrimiento de la persona. Por lo anterior, esta argumentación se desarrolla sobre la siguiente hipótesis: dado que el FMI parte del concepto reduccionista de pobreza y no diferencia entre país pobre y personas pobres, sus intervenciones, difícilmente, pueden reducir la incertidumbre y el sufrimiento de las personas pobres.

Para validar el contenido de esta hipótesis, el trabajo tiene cuatro secciones aparte de esta introducción. En la primera se revela la importancia de tener en cuenta la incertidumbre en el análisis de la pobreza. La segunda analiza las políticas que aplica el FMI, para reducir la pobreza en los países donde ejecuta sus intervenciones. La tercera expone, los acercamientos que ha tenido Colombia con el FMI, junto con las implicaciones económicas que tuvieron los ajustes del FMI sobre la economía colombiana y, particularmente, sobre el aumento o disminución de la incertidumbre en los habitantes del país y, por ende, en la pobreza. Finalmente, se concluye expresando que las intervenciones del FMI en Colombia, en la medida en que garantizaron la rentabilidad del capital, reafirmaron las condiciones que fundamentan la incertidumbre de los pobres del país.

\section{Incertidumbre - Pobreza}

La pertinencia de la incertidumbre, como una arista relevante, a la hora de analizar la pobreza reside en el hecho de que va más allá de la concepción reduccionista de la pobreza que define como pobre aquel hogar/individuo que carece del ingreso mínimo para cubrir sus necesidades más elementales. La inclusión de la incertidumbre en el análisis de la pobreza busca dar una explicación más amplia de la misma, dado que parte de la premisa de que esta es un universo en sí mismo, que debe ser explorada con el fin de comprender la persistencia de la pobreza.

Casas (2009) cuestiona la manera habitual de concebir la pobreza, una vez revisados varios conceptos de la pobreza, dado que en ellos aún faltan elementos en la noción que hace referencia a las dimensiones humanas. Uno de estos o que al menos no se encuentra ampliamente discutido, en los estudios sobre la pobreza, es la incertidumbre. De ahí que Casas (2009) concluya: 
La incertidumbre es trascendental (...) en el marco de construir una aproximación al concepto de pobreza, porque cuando la gente está habitada por la perplejidad, no puede resolver asertivamente sus diversas situaciones. El enemigo de la miseria y de la muerte los acecha, y ante tal catástrofe se buscan soluciones (...) en todos los sitios (...) Sin embargo, cuando todos los intentos fracasan, se recurre, desesperadamente, a cualquier acción para sobre-vivir. Por lo anterior, se puede concluir que el supuesto del que parte la teoría microeconómica (la racionalidad inherente al ser humano y sus posibles puntos de equilibrio) no se puede cumplir, cuando en los seres humanos está presente la incertidumbre, vista como un punto de inflexión en que la vida misma es zozobra, angustia, terror ante lo que viene con el futuro. Es, en síntesis, la transformación de los seres humanos en un producto de su propia enajenación, cuando el mercado y todos los agentes sellan sus candados y suprimen su respaldo (p.78).

En consecuencia, la incertidumbre es el elemento que se pretende adicionar al análisis de la pobreza. Y a partir de este se examina la incidencia de las intervenciones del FMI sobre la pobreza en Colombia; es decir, se busca analizar, cómo, a partir de una definición de pobreza que involucra la incertidumbre, las intervenciones del FMI inciden en la pobreza en el país. Partiendo de la concepción propia de pobreza y de la hipótesis que se planteó en la introducción, es necesario explicitar las razones por las cuales la incertidumbre debe tenerse en cuenta a la hora de abordar el análisis de la pobreza.

\section{La incertidumbre de los pobres}

Habitualmente, la pobreza ha sido definida como falta, escasez e incapacidad de satisfacer necesidades básicas para el ser humano. Esto conlleva a preguntarse sobre lo que se entiende por necesidad y sobre este aspecto aún no hay un consenso general sobre lo que debería ser considerado como necesidades básicas y, más aún, su nivel de satisfacción. Sin embargo, sí se reconoce que la insatisfacción de las necesidades, se traduce en pobreza. Así, se podría sintetizar que la pobreza es carencia o insuficiencia de un atributo con relación a un umbral. Por tanto, si las personas se sitúan por debajo del umbral predefinido serán consideradas pobres respecto del atributo elegido (Coudouel, Hentschel y Wodon, 2002).

No obstante, una cosa es señalar si se es pobre bajo cualquier atributo y otra analizar si su pobreza se ve reforzada por medio del surgimiento de otros elementos que acechan la existencia de la persona. Es decir, imagínese ¿qué sucedería al enfrentarse a la pérdida secuen- 
cial de la posibilidad de satisfacer sus necesidades desde su necesidad menos relevante a la más fundamental, en el presente, reconociendo que en el pasado sí las podía resolver? Seguramente el individuo comparará su pasado frente a su presente y que, ante este escenario, surgirá una visión sobre su futuro. Colocar al individuo ante la imposibilidad de satisfacer sus necesidades, es ubicarlo en un entorno de pobreza. Aquí es donde surge la necesidad de incluir la incertidumbre al análisis de la pobreza.

Pindyck \& Rubinfeld (2009) comentan la diferencia que hizo Frank Knight entre incertidumbre y riesgo. Así la incertidumbre se refiere a “(...) situaciones en las que hay muchos resultados posibles, pero se desconocen sus probabilidades". En cambio, el riesgo se refiere a situaciones en las que se pueden "(...) enumerar todos los resultados posibles" y se conoce “(...) cuál es la probabilidad de que se produzcan” (p.178). Por tanto, es posible agregar al análisis de la pobreza la incertidumbre si se concatena dicha conceptualización al cúmulo de situaciones desfavorables a las que se ve abocada una persona pobre con el desconocimiento que le plantea a esta la angustia (impotencia, terror, zozobra) de qué deparará el mañana. En ese instante, la incertidumbre es el resultado de un cúmulo de sensaciones que conllevan a la intensificación del sufrimiento de la persona.

La importancia de la incertidumbre, reside en el hecho de que en el devenir de los seres humanos, esta aparece como un peligro en una situación: la incontrolable. Es decir, habría dos tipos de incertidumbre: controlable e incontrolable. Cada una tiene sus características, pero la más importante de cada una de ellas es que la primera es una disposición, mientras que la segunda es un estado de ánimo. La incertidumbre como disposición, se da cuando la persona administra su incertidumbre cuando manifiesta con ilusión su futuro. En esta situación se admite incertidumbre -es decir, alberga oportunidades para el triunfo o reducir $\mathrm{su}$ incertidumbre, por ejemplo cuando las personas van a sitios especializados en la lectura de la mano, las cartas-. Aquí la voluntad humana es más fuerte que la incertidumbre, ya que ahí el sujeto es más consciente de su disposición. De hecho, permite que la incertidumbre entre en su vida, pero cuando, por alguna razón, decide acabarla, lo hace a través del desalojo de esa disposición, aunque eso implique entrar a otro momento de incertidumbre.

La incertidumbre como estado de ánimo (la incontrolable), es algo que el individuo quiere eliminar de su existencia porque su invasión lo hace sentir impotencia, ya que no tiene control sobre ella -este tipo de incertidumbre abre el camino al sufrimiento, puesto que el 
individuo no puede escapar-. Y como no lo tiene, la incertidumbre es más fuerte, menoscabando su autoestima, puesto que no le permite tener certezas sobre el futuro y el devenir de su existencia, porque entiende que todas las variables que lo determinan están fuera de su control, hecho que hace más intenso este malestar, hecho que podría conducir al sujeto a la adopción de comportamientos sociales bajo otra racionalidad (Elster, 1991).

En ambos casos, hay incertidumbre pues si no la hubiese esta no representaría ningún problema para el comportamiento y la existencia del individuo. De hecho, la incertidumbre es inherente al ser humano, configurándose en la expresión y en la única voz posible de quienes están atados a la pobreza. Pero una voz repudiable que exige la urgente transformación de las expectativas económicas en realidades concretas, es decir, teorizar y pensar en un sistema que brinde la posibilidad de colocar al ser humano por encima de la economía y sus resultados.

En estos términos, no se bosqueja una solución ideal a la problemática de la pobreza, sino su reducción en términos reales, tangibles, posibles, no sólo pensados en un contexto inmediato. Así pues, se plantea un principio en el que el papel del Estado, en conversación con los pobres, se vuelve trascendental, relevante y va más allá de las políticas asistencialistas centradas en estos, sin que los pobres pierdan su lugar, su espacio, sus expectativas, sueños, esperanzas, desilusiones y fracasos, sus mundos posibles, en suma, su humanidad.

Desde esta postura, el mismo pobre tendría la posibilidad de elegir, administrar y re-crear, su incertidumbre que habría de entenderse como un bien común de los individuos, en el sentido voluntario. En síntesis, si el individuo pobre es invadido por la incertidumbre incontrolable, la cual no le permite tener certezas sobre el futuro y el devenir de su existencia a través del mismo, debido a que es generada por factores exógenos se dirá que su pobreza se incrementó ya que las variables que determinan a la incertidumbre están fuera de su control.

\section{Politicas del FMI para reducir la pobreza}

Este acápite explicita cinco aspectos del FMI, frente a la reducción de la pobreza: origen, función, mecanismos de préstamos, concepción y políticas para reducir la pobreza. 


\section{- Origen}

El FMI surgió en Julio de 1944, en la conferencia de Bretton Woods-Estados Unidos, con el propósito de evitar las desastrosas políticas económicas que intervinieron en la depresión de los años treinta (Clift, 2004). Sin embargo, inició actividades en Diciembre de 1945. El organismo tiene como propósitos contribuir al funcionamiento adecuado de la economía global, así como facilitar, a través de los tipos de cambio, la actividad económica entre los países miembros. Este intenta encauzar la economía mundial hacia la estabilidad, puesto que cree que en ella el sistema económico resistiría los choques exógenos presentados en cualquiera de los 188 países miembros (FMI, 2013).

El FMI ha experimentado algunas modificaciones. Entre ellas están: el cambio de la política cambiaria (transición de un tipo de cambio fijo a uno flexible); el surgimiento del derecho especial de giro (como activo de reserva); y el ofrecimiento de nuevos servicios (asesorías técnico-económicas, para el crecimiento y la lucha contra la pobreza (SCLP), para los Países Pobres Muy Endeudados (PPME), entre otros). Estas modificaciones surgieron producto de la globalización, que le ha impuesto nuevos retos; tales como fortalecer el sistema financiero mundial y propiciar el debate en torno del avance de la lucha contra la pobreza en los países de bajo ingreso (Clift, 2004).

Para la entidad, el Comercio Internacional (CI) es un elemento unificador, que permite a los países conseguir progresos en los niveles de vida de sus habitantes. Sin embargo, el FMI reconoce que la globalización, por un lado, amplía el riesgo de que se presenten crisis financieras y, por otro, que los países de bajo ingreso no se han beneficiado de las ventajas que esta trae consigo (Clift, 2004). Esto ha conducido a que el Fondo se una con el Banco Mundial (BM), y la Organización Mundial del Comercio (OMC) con el objeto de trabajar conjuntamente y que sus acciones se complementen, aunque cada institución tenga objetivos disímiles ${ }^{3}$ (Clift, 2004).

\footnotetext{
${ }^{3}$ El FMI se concentra en la política macroeconómica y el sector financiero; el BM en el desarrollo y la disminución de la pobreza; y la OMC busca liberalizar el comercio mundial.
} 


\section{- Función}

Esta procede de los fines señalados en el artículo $1^{\circ}$ del convenio constitutivo del FMI. Este dirige toda la actividad en lo económico y político. Los seis fines son, según Brau (2001):

Fomentar la cooperación monetaria internacional (...) Facilitar la expansión y el crecimiento equilibrado del $[C I]$ (...) Fomentar la estabilidad cambiaria (...) Coadyuvar a establecer un sistema multilateral de pagos para las transacciones corrientes que se realicen entre los países (...) Infundir confianza a los países (...) acortar la duración y aminorar el grado de desequilibrio de las [balanzas de pagos] de los países (p.1).

El ente facilita recursos a los países miembros que pasan problemas en Balanza de Pagos (BP) con la condición ineludible de que se comprometan a poner en marcha medidas de ajuste económico que permitan corregir los problemas estructurales por los que atraviesan sus economías. Para lograr esto, la institución utiliza tres mecanismos: 1) supervisión que consiste en que el FMI asesora al país realizando evaluaciones de la situación económica y determina si es necesario hacer ajustes; 2) asistencia técnica que aconseja poner en marcha políticas fiscales, monetarias y cambiarias; y 3) asistencia financiera que pretende brindarle a los países cierto margen de maniobra para corregir sus problemas de BP (Brau, 2001).

Lo anterior, según Sachs (2013) revela que el FMI debe profundizar en su análisis, puesto que los países más necesitados requieren políticas que vayan más allá de solo apretarse el cinturón presupuestario. El Fondo se declara inocente argumentando que él ofrece sus servicios sólo a aquellos países que solicitan su auxilio por medio de la carta de intención, donde el país manifiesta el servicio ${ }^{4}$ al que se quiere acoger, expresando que está dispuesto a hacer los ajustes e incluso a adoptar las medidas que la entidad sugiera. Esta puede aceptar o rechazar la propuesta en la carta. Si acepta, envía a sus miembros al país para colocar en marcha el ajuste; sino recomienda hacer ajustes y después de realizados, el FMI decide si acepta o no (Clift, 2004).

\footnotetext{
${ }^{4}$ Entre estos están: los acuerdos de derecho de giro, el servicio ampliado, el servicio para el crecimiento y la lucha contra la pobreza, el servicio de complementación de reservas, y la asistencia de emergencia.
} 


\section{- Mecanismos de préstamos}

Los créditos son de carácter condicional, puesto que el organismo cree que si no se condiciona al país prestatario, es probable que no se cumplan los objetivos acordados. El objetivo primordial de cualquier crédito es la corrección de los problemas en BP; para garantizar dicha corrección, la institución entrega el crédito de forma escalonada, es decir, da los recursos en la medida en que se vayan efectuando las metas trazadas en las políticas de ajuste ${ }^{5}$. Para comprobar si el país está cumpliendo con los compromisos, el fondo tiene tres modalidades de seguimiento (la supervisión de la política económica nacional, la supervisión mundial de la tendencia y evolución de la economía mundial, y la supervisión regional) que se caracterizan por vigilar la política económica nacional en los campos fiscal, monetario, cambiario, industrial, social y laboral. Finalmente, cabe señalar que el Fondo no es un organismo de ayuda ni un banco de desarrollo, sino concede crédito para que los países superen problemas de BP y restablezcan el crecimiento económico sostenible (Clift, 2004). De ahí que se infiera que el FMI no tiene un compromiso con la pobreza y lo que hace, en último término, es asociarla con problemas en BP.

\section{- Concepción de la pobreza del FMI}

El FMI no tiene un compromiso directo con la pobreza, por ende su efecto en cuanto a esta es indirecto, a través del proceso de ajuste. Asimismo, para el fondo la pobreza es una cuestión de un bajo PIB per cápita, como se infiere de Clift (2004):

El FMI es una institución monetaria, no de desarrollo, pero le compete un papel importante a la hora de reducir la pobreza en los países miembros (...) el FMI ha prestado ayuda a los países de bajo ingreso para que implementen medidas de política que fomenten el crecimiento y eleven el nivel de vida (p. 46).

\footnotetext{
${ }^{5}$ Tales como reformas en el sector tributario y financiero, privatización de empresas públicas, flexibilidad en el mercado laboral, reducción del gasto público, entre otras.
} 
Por ende, el FMI entiende la pobreza como una cuestión de insuficiencia de renta. Por ello, clasifica a los países basado en su nivel de renta (alta, media y baja) y dictamina si son pobres o no. Además, se puede aseverar que el FMI ve que la pobreza puede ser eliminada, a través de las políticas de ajuste -el asistencialismo- que este recomienda y que tienen por objetivo reparar los problemas en BP. Pero ese enfoque reduccionista podría ser insuficiente a la hora de encarar la pobreza, puesto que esta es de carácter multidimensional. Por ende, el FMI habla de países pobres y no de personas pobres.

\section{- Políticas del FMI para reducir la pobreza}

La entidad ha revaluado su postura y ha enunciado que es preciso un nuevo enfoque en la lucha contra la pobreza. Este debe ajustarse y focalizarse en las necesidades más apremiantes de los pobres. Del mismo modo se requiere una ampliación del concepto de pobreza, un crecimiento económico veloz y la inclusión de los pobres en los mercados (Clift, 2004). Lo anterior, según el Fondo, ayudaría a reducir la pobreza, porque los pobres se harían partícipes de las ventajas que proporcionan el crecimiento y la actividad económica de un país.

El FMI ha pronunciado que sus energías están concentradas a prescribir estrategias que combatan eficazmente la pobreza. Ellas buscan fortalecer la soberanía del país, el desarrollo integral y ampliar la participación pública. Para lograr estos objetivos, la entidad recomienda instaurar medidas macroeconómicas, estructurales y sociales; para que la población pobre sea incluida al mercado y así, las mejoras que se vayan adquiriendo sean repartidas entre esta población, de manera que la eficacia y eficiencia del enfoque no se diluya (Clift, 2004).

\section{Implicaciones de los acuerdos con el FMI en Colombia}

Colombia se ha acercado a los dominios del FMI, principalmente, en cuatro ocasiones sin embargo, este mantiene conversaciones bilaterales con sus miembros a través de visitas anuales-. La primera, sucedió en el gobierno de Carlos Lleras (1966-1970). Cuando el país afrontaba problemas cambiarios, razón por la cual el Fondo recomendó devaluar el peso, y liberalizar la economía. Sin embargo, se adoptaron políticas contrarias a las recomendadas sin que las relaciones se vieran afectadas (Giraldo, 2001). 
La segunda, ocurrió bajo el gobierno de Belisario Betancur (1982-1986) debido, también, a una crisis cambiaria por la disminución de las reservas internacionales del país. El Fondo abogaba por una devaluación para el año 1984, y sugirió firmar un acuerdo. El país reclamó una monitoría, que fue aceptada por la institución. La monitoría se sustentó en el cumplimiento de ciertas metas macroeconómicas, con el fin de que los bancos externos recobraran la confianza en el país y, de este modo, desembolsar recursos ${ }^{6}$ necesarios (Giraldo, 2001).

La tercera, aconteció en la administración de Pastrana (1998-2002), en Diciembre de 1999. El país no afrontaba una crisis cambiaria, que es la principal razón por la cual se pactan acuerdos con el fondo. Aquí, por primera vez, el país firmó un acuerdo que el FMI denomina crédito de contingencia (stand-by). Esta negociación tuvo tres revisiones que implicaron su continuidad. Se había acordado inicialmente una duración de tres años, pero debido al incumplimiento de las metas macroeconómicas, en el 2002 hubo de renovarse por dos años más y en 2005 se renovó por un año más.

La cuarta, sucedió en el segundo gobierno de Uribe (2006-2010), el 11 de Mayo de 2009, con el objetivo de proteger la economía nacional de los efectos de la crisis mundial desatada en 2008. En esa ocasión, el gobierno pidió US\$10.500 millones. Sin embargo, no fue un acuerdo formal sino una invención del FMI, llamada Línea de Crédito Flexible (como respuesta a la crisis), que no sujetó a ninguna condición por parte del FMI al país. Desde la fecha indicada hubo dos reajustes a la cifra. El primero se presentó el 7 de mayo de 2010 cuando el país le pidió al Fondo US\$3.460 millones; el segundo se dio el 9 de mayo de 2011 cuando se reajustó la cifra a US\$6.200 millones (FMI, 2011). Sin embargo, el país no usó los recursos.

\section{Implicaciones económicas de los ajustes del FMI}

Los ajustes que el FMI recomienda a un país miembro se fundamentan en contraer las políticas monetaria y fiscal, así como vigilar variables externas (tipos de cambio, la inflación, la deuda externa y las reservas internacionales) con el fin de garantizar la viabilidad de la

\footnotetext{
${ }^{6}$ Aquí surgieron los créditos Jumbo, Concorde, Challenger y Hércules, cada uno por más de mil millones de dólares.
} 
BP, la estabilidad macroeconómica y el desenvolvimiento de la demanda agregada del país, de modo que este pueda responder por sus pagos externos (Gamarra, 2003).

No obstante, los movimientos de las variables externas son inducidos por la dinámica de variables internas -impuestos, consumo, entre otras-, lo que permite inferir que al FMI no le interesa, de manera directa, el crecimiento económico y el desarrollo del país. Pues si le interesaran dedicaría sus esfuerzos a corregir los desequilibrios ${ }^{7}$ internos, en vez de los externos, puesto que en la solución de los primeros, radica el verdadero potencial económico que puede alcanzar un país en el largo plazo, por medio de políticas económicas que promuevan y estimulen la inclusión de los agentes económicos a la conformación del producto nacional.

En consecuencia, una política orientada a corregir los desequilibrios internos, no sólo genera un aumento de la oferta y demanda, sino también una simbiosis entre la eficiencia y la equidad, que se reflejaría en estabilidad macroeconómica. De esta forma, el país podría responder por sus pagos externos sin contratiempos, es decir, se alcanzarían los objetivos -viabilidad en BP y estabilidad macroeconómica- que el FMI pretende alcanzar en cada acuerdo, sin sacrificar el potencial económico del país. Sin embargo, el FMI se concentra en la corrección de los desequilibrios externos y la ejecuta por medio del control y supervisión, principalmente, de las variables inflación y déficit en BP. Estas variables resultan trascendentales en el ajuste contraccionista que hace el Fondo, porque a través de ellas puede determinar si la demanda agregada del país es sostenible o no en el tiempo, de acuerdo con el ritmo de crecimiento de la economía nacional (Gamarra, 2003).

A juicio del FMI, lo anterior se evidencia en los desequilibrios fiscales ${ }^{8}$, que provocan un deterioro en la BP. A su vez, si se comprueba el deterioro, se establece la pérdida de credibilidad internacional del país y, por ende, se abre la posibilidad de la intervención del Fondo en este. Cuando el FMI interviene en una economía le recomienda al Gobierno que promueva reducción de los salarios reales, privatizaciones y leyes que ayuden al cumpli-

\footnotetext{
${ }^{7}$ Se refiere a cuando hay una diferencia significativa entre oferta y demanda agregadas que se manifiesta en un desequilibrio interno (inflación y desempleo) o un desequilibrio externo (déficit en cuenta corriente).

${ }^{8}$ Según el FMI los desequilibrios son resultado de la no profundización de las reformas estructurales: flexibilización de los mercados, ajustes fiscales severos y saneamiento del sistema financiero.
} 
miento del acuerdo. Generalmente, el ente solicita realizar una contracción de la demanda agregada, lo que implica una reducción del gasto de los agentes económicos del país, para propiciar, con ello, la corrección de los desequilibrios macroeconómicos.

El Fondo sustenta que la severidad fiscal y el control de la inflación dinamizan el crecimiento económico, que implica para los inversionistas de una economía reducir su incertidumbre y la preservación de la rentabilidad de sus activos. En cambio, para Gamarra (2003), el ajuste del FMI debería centrarse en los desequilibrios internos, y no en los externos, ya que los correctivos aplicados a los primeros fortalecerían el sistema productivo y, con este, se generarían empleos productivos. Sin embargo, la solución al desempleo, para el Fondo se halla en la flexibilización del mercado laboral (Robledo, 2007), ya que con esta se lograría que la demanda de trabajo consiga que la tasa natural de desempleo sea compatible con el nivel de ocupación, debido a una disminución de los salarios.

No obstante, la búsqueda del equilibrio externo o interno no garantiza una solución óptima para los seres humanos, puesto que en ellos sólo participan los agentes que poseen dinero (Keynes, 2014). Esto revela que el mercado excluye a los que no tienen dinero, y como el equilibrio se alcanza únicamente en el mercado, los que no cuentan con dinero, no participarían ni en el mercado ni en el equilibrio económico. Por tanto, se infiere que al FMI le interesa reducir la incertidumbre, principalmente de los inversionistas. Y con ello solidifica las reglas del capitalismo, para alcanzar su objetivo final: la ganancia. Marx (1975) dice:

Los orígenes de la primitiva acumulación pretenden explicarse relatándolos como una anécdota del pasado. En tiempos muy remotos, había, de una parte, una minoría trabajadora, inteligente y sobre todo ahorrativa, y de la otra un tropel de haraganes, que derrochaban cuanto tenían (...) Así se explica que mientras los primeros acumulaban riqueza, los segundos acabaron por no tener ya nada que vender más que su pellejo. De este pecado original arranca la pobreza de la gran mayoría, que todavía hoy, a pesar de lo mucho que trabajan, no tienen nada que vender más que sus personas, y la riqueza de una minoría, riqueza que no cesa de crecer, aunque haga ya muchísimo tiempo que sus propietarios han dejado de trabajar (p. 607).

Sin embargo, los acuerdos firmados con el FMI, incrementan la incertidumbre para los pobres, porque se fortalecen las reglas que afianza la situación que ellos repudian. Tales reglas favorecen al capital y van en contra de las prioridades de los pobres: la subsistencia, el 
trabajo, entre otras. Beluche (2007, p.19) expresa la "constancia con que la pobreza acompaña al sistema capitalista demuestra que ella es producto de las leyes de funcionamiento del sistema". Por lo cual, lo que reclaman los pobres, no es menos inflación o estabilidad macroeconómica, sino que su situación se transforme. No obstante, el FMI hace caso omiso de lo anterior y, en todos los acuerdos sugiere hacer ajustes en las políticas: macroeconómicas y financieras, monetaria y cambiaria ${ }^{9}$, y la fiscal ${ }^{10}$. A continuación, se hace un análisis de lo ocurrido tanto en la monitoria como en el acuerdo que Colombia firmó con el FMI.

\section{Monitoría}

En Colombia, durante la década de los ochenta, se presentaron desequilibrios macroeconómicos, provocados por el debilitamiento de los mercados internacionales, la caída de los precios del café y la crisis de la deuda latinoamericana (Ocampo, Bajraj \& Martin, 2001). Por lo anterior, el país pactó una monitoría en 1984 con el FMI, ya que a juicio de este el modelo de industrialización por sustitución de importaciones provocó que la industria colombiana tuviera una estructura monopólica y oligopólica, que la hizo incapaz de competir internacionalmente. De ahí que el Fondo le exigió al país adoptar una política de austeridad fiscal y ajustar aspectos cambiarios, comerciales y de las reservas internacionales.

En materia cambiaria, el FMI pidió que el país devaluara el peso para ganar competitividad y evitar la fuga de capitales; respecto del comercio, solicitó desregulación de la economía; y en cuanto a las reservas solicitó hacer esfuerzos para evitar la disminución de estas. Con estas medidas, según el Fondo, se conseguiría normalizar las relaciones con la banca mundial, devolviéndole a la nación la credibilidad crediticia que requería para financiar proyectos en sectores clave como el petrolero ${ }^{11}$ (Garay, 2004).

Para 1985, Colombia hizo una solicitud de un crédito por US $\$ 1.000$ millones ante el BM. Este ente aprobó la solicitud debido a que el FMI acordó unas metas trimestrales con el

\footnotetext{
${ }^{9}$ Las variables a vigilar son la inflación y las reservas internacionales para garantizar el sostenimiento de la BP.

${ }^{10}$ A través de la instauración de reformas estructurales se busca que el déficit fiscal consolidado se corrija y que el Estado reduzca su intervención en la economía.

${ }^{11}$ El gobierno nacional requería recursos para la financiación de las inversiones en los sectores petrolero (Caño Limón) y carbonífero (Cerrejón), cuyos productos se perfilaban como exportables.
} 
país de cumplimiento obligatorio para que los recursos fueran desembolsados. A juicio del BM y del FMI, el país obtuvo mejorías que se reflejaron en el progreso de las condiciones de acceso al crédito internacional, la reducción del déficit comercial, y las perspectivas favorables, en materia de exportación, promovieron en el Gobierno de Betancur una reforma que pretendía liberalizar y desgravar paulatinamente el CI (Garay, 2004).

La referida reforma, no obtuvo los resultados esperados según Garay (2004), puesto que la industria nacional presentó tasas negativas de crecimiento entre 1981 a 1983 . Por ejemplo, las exportaciones no tradicionales y totales disminuyeron un $14 \%$ y un $10 \%$, respectivamente. Sin embargo, la economía colombiana logró estabilizarse en aspectos fiscales y financieros, que permitieron promover, entre 1985 a 1989, la liberalización de la economía nacional dado el aceptable desempeño de los agregados macroeconómicos. Así el país, incentivado por el FMI, a inicios de los noventa, aceptó desmantelar aranceles y liberalizar la economía para ponerse en tono con la apertura económica.

Sin embargo Krugman, citado por Robledo (2007), señala que el éxito económico de un país depende de que los productores nacionales vendan, en primera instancia, al mercado interno y luego al mercado externo. No obstante, Colombia abrió su economía sin haber consolidado su mercado interno, lo que puso en evidencia la debilidad del aparato productivo del país. Este proceso se tradujo en la reducción de aranceles, como paso previo al proceso de apertura iniciado en 1990. Por ejemplo, el arancel promedio pasó del 31\% en 1985 al 27\% en 1988; la tarifa de bienes de consumo duradero pasó del 47\% al 41\%; la de materias primas de $28 \%$ a $24 \%$ y la de bienes de capital de $27 \%$ a $22 \%$ (Garay, 2004).

A inicios de los 90, el país se hallaba inmerso en la apertura, que tenía según Garay (2004) dos objetivos: 1) dirigir gradualmente la producción nacional hacia los mercados externos con el fin de incrementar las exportaciones; y 2) facilitar la entrada de importaciones de bienes de capital para aumentar la capacidad productiva de la industria doméstica. Pero el desarrollo del sector externo hacía pensar que el objetivo de la apertura no se estaba alcanzado, ya que el aumento de importaciones y exportaciones no era el esperado (Misas, 2002). Internamente, entre 1990-1995, se presentó un significativo crecimiento de la demanda doméstica colombiana que se detuvo, desde finales de 1995, cuando la economía experimentó un estancamiento, producto de las altas tasas de inte- 
rés, la desaceleración de la construcción, la revaluación del peso y la elevada inflación (Garay, 2004).

Para 1999 el aumento del déficit en BP, sumado a la desaceleración del crecimiento económico, con un desempleo del 20\% y una devaluación real (alrededor del 24\%), desnudaron que el crecimiento alcanzado por Colombia, en la primera mitad de los noventa, fue causado por el aumento de la demanda agregada generada a través del incremento del servicio de la deuda interna y externa (Garay, 2004). Esto produjo problemas de liquidez y de solvencia en gran parte de los agentes privados, lo cual se transmitió al sector financiero, deteriorando la calidad de la cartera. Por ejemplo, entre 1997 y 1998 se cerraron 5 mil pequeñas y medianas empresas y el 40\% de las mil empresas más grandes del país perdieron una suma equivalente a casi cinco puntos del PIB. En cuanto a los hogares, estos financiaron su consumo con créditos que cada vez se hacían más caros e impagables, que se derivó en la crisis del sistema $\mathrm{UPAC}^{12}$ ya que al finalizar 1998 había 187 mil deudores morosos y la cartera vencida sumaba más de 1.29 billones de pesos (Robledo, 2007). Todo esto sucedió porque los créditos no se hallaban respaldados por aumentos en la productividad de los factores, sino en aumentos de la especulación (Gamarra, 2003).

Lo anterior, se evidenció en el cierre de los mercados de capitales para el país en 1999, que obligó al Banco de la República a subir las tasas de interés. Esta maniobra esparció, un alto nivel de incertidumbre y riesgo, lo que produjo que el sistema financiero interrumpiera la concesión de créditos a los agentes económicos del país. En ese año, se dejó el sistema de bandas cambiarias para acoger el sistema de tasa de cambio flexible (Gamarra, 2003). La acumulación de los anteriores factores mostró que era insostenible la burbuja del crecimiento económico del país, vivido en el primer lustro de los noventa, llevándolo a experimentar la peor crisis económica de Colombia. En ese escenario, en diciembre de 1999, el país firmó el acuerdo con el FMI, a pesar de que según Garay (2004) el país no requería suscribir dicho acuerdo.

Acuerdos stand-by

\footnotetext{
${ }^{12}$ La sigla significa unidad de poder adquisitivo constante. Este sistema se usó para calcular el costo de créditos de vivienda. Ir a: http:// www.banrep.gov.co/sites/default/files/paginas/met_calculo_UPAC.pdf.
} 
El análisis de los acuerdos firmados en los años 1999, 2002 y 2005, se hace de manera conjunta porque los dos últimos no se firmaron por condiciones distintas a las del primero sino por el incumplimiento de las metas pactadas en cada acuerdo, que obligó al FMI a hacer nuevos ajustes. Bajo los acuerdos, el gobierno argumentó que se buscaba promover el crecimiento económico sostenible, el aumento del empleo, una inflación más baja y la reducción de la pobreza. Para alcanzar estos objetivos, el FMI le exigía al Estado reducir su participación en la economía y, promover la liberalización de todos los mercados. El análisis de estos acuerdos se hace a la luz de los ajustes que exigió el FMI efectuar en materia de política económica.

\section{Políticas macroeconómica y financiera}

El Fondo insistió en que el país debía perseguir el objetivo de consolidar un crecimiento económico sostenido, alrededor del 4\% durante todo el periodo del acuerdo, que permitiría la generación de oportunidades de empleo para los colombianos. Además, pretendió que la deuda externa se estabilizara alrededor del $44 \%$ del PIB, pero este objetivo no se alcanzó durante el periodo de los acuerdos (ver cuadro 1). Asimismo, buscaba el fortalecimiento del sistema financiero, con el fin de que se pudiera alcanzar la estabilidad macroeconómica. De hecho, Giraldo (2000) expresó que el acuerdo favoreció a los que debían en dólares:

Desde lo financiero, tiene como objetivo permitir que los inversionistas externos se aseguren que existe la liquidez necesaria para financiar su salida (...) El Acuerdo se hace para facilitar la salida de los capitales; eso se aprecia en las condiciones del préstamo, que curiosamente no aparecen en el texto divulgado a la opinión pública. Textualmente, ellas rezan (...) las autoridades pueden hacer uso de la cantidad solicitada (...) de acuerdo con el cronograma establecido, excepto en el momento en que Colombia incurra en atrasos en los pagos externos del sector público. Imponga o intensifique restricciones sobre los pagos y transferencias de las transacciones internacionales corrientes (pp.4 y 5). 
Cuadro 1.

Metas y resultados en Colombia bajos los acuerdos con el FMI (1999-2007).

\begin{tabular}{|c|c|c|c|c|c|c|c|c|c|}
\hline VARIABLE & 1999 & 2000 & 2001 & 2002 & 2003 & 2004 & 2005 & 2006 & 2007 \\
\hline $\begin{array}{l}\text { Meta de crecimiento } \\
\text { económico }(\%)\end{array}$ & -3.5 & 3 & 3.8 & 4.8 & $2-2.5$ & $>3$ & 5.1 & 4.5 & 4 \\
\hline Resultado & -4.2 & 2.7 & 1.4 & 1.6 & 3.9 & 4.8 & 4.7 & 6.8 & 7.5 \\
\hline Meta de inflación (\%) & 11 & 10 & 8 & 6 & 5.9 & 5.5 & 5 & 4.5 & 4 \\
\hline Resultado & 9.2 & 8.7 & 7.6 & 7 & 6.5 & 5.5 & 4.85 & 4.48 & 5.69 \\
\hline $\begin{array}{l}\text { Meta Déficit Cuenta } \\
\text { Corriente de la BP (\%PIB) }\end{array}$ & -1.3 & -2.4 & -3.1 & -3.2 & -2.2 & -1.8 & -3 & -3 & -2.7 \\
\hline Resultado & 0.8 & 0.8 & -1.5 & -1.9 & -1.8 & -2.2 & -2.7 & -3 & -2.8 \\
\hline Meta Déficit Fiscal (\%PIB) & n.d. & n.d. & n.d. & 4 & 2.45 & 2.1 & 1.6 & 1.3 & n.d. \\
\hline Resultado & 5 & 3.5 & 3.3 & 3.7 & 2.7 & 1.3 & n.d. & 4.2 & 3.6 \\
\hline $\begin{array}{l}\text { Meta Reservas } \\
\text { Internacionales (miles de } \\
\text { mill US } \$ \text { ) }\end{array}$ & -21.5 & 18.1 & 7 & 6.1 & 10.5 & 13.2 & 14.7 & 15.2 & 15.6 \\
\hline Resultado & 8.1 & 9 & 10.2 & 10.8 & 10.9 & 13.5 & 14.9 & 15.4 & 20.9 \\
\hline Meta Deuda Pública (\%PIB) & 34.2 & 34.1 & 33.8 & 34 & 49.9 & 51.9 & 47.4 & 47.8 & 45.2 \\
\hline Resultado & 42.2 & 47.2 & 50.5 & 55 & 60 & 53 & n.d. & 59.8 & 55.4 \\
\hline $\begin{array}{l}\text { Meta Déficit Sector Público } \\
\text { Consolidado (\%PIB) }\end{array}$ & -6 & -3.5 & -2.4 & -1.3 & -2.5 & -2.5 & -2.5 & -1.6 & -1.6 \\
\hline Resultado & -10 & -3.3 & -3.2 & -3.6 & -2.7 & -1.3 & n.d. & -0.8 & -0.8 \\
\hline Resultado Desempleo (\%) & 20.1 & 19.7 & 18.2 & 17.6 & 16.4 & 15.4 & 13.6 & 12.03 & 11.13 \\
\hline
\end{tabular}

Nota: n.d. significa no disponible.

Fuente: construcción propia con datos de los acuerdos, las bases de datos del Banco de la República y del Departamento Nacional de Planeación de Colombia. 
Una de las preocupaciones para el FMI, era corregir la debilidad del sistema financiero colombiano. Esta debilidad se buscó corregir por medio de regulación, supervisión de los mercados de capitales y reestructuración financiera - privatización de los bancos públicos(Acuerdo, 1999). Con la idea de subsanarla, en el numeral 6 del Acuerdo (1999, p.6) se expresa que es necesario: "un impuesto del 0,2 por ciento a las transacciones financieras para ayudar a financiar programas de alivio a los deudores hipotecarios y para fortalecer los bancos públicos y las cooperativas financieras”. Este impuesto ${ }^{13}$ salvó al sistema financiero de la quiebra. La situación de salvamento permite señalar que cuando hay una crisis se socializan las pérdidas y en épocas de auge se privatizan las utilidades (Stiglitz, 2009). El FMI aducía que la debilidad se debía a la existencia de bancos públicos. De ahí que el Estado debía, como está en el numeral 29 del mismo acuerdo, privatizarlos.

Finalmente, en los acuerdos (1999, 2002 y 2005) hablan de la necesidad de que el Gobierno se comprometa con los principios de la OMC. Es decir, Colombia tenía que liberalizar el mercado de bienes y servicios, lo que implicaba la eliminación gradual de subsidios a la producción nacional, la eliminación de aranceles a la producción extranjera, así como renunciar a la aplicación de políticas proteccionistas.

\section{Las políticas monetaria y cambiaria}

Todos los acuerdos insistieron en el control de la inflación y en la eliminación de las restricciones cambiarias. El FMI señaló que el acuerdo se rompía si el gobierno colocaba restricciones sobre los pagos y transferencias de las transacciones internacionales corrientes (Giraldo, 2001). De hecho la estabilidad macroeconómica, perseguida por el FMI, quedó sujeta a los vaivenes de los flujos de capital, que pudo tener un efecto negativo para dicha estabilidad con el consecuente debilitamiento del sector financiero. Así, en materia de los ajustes hechos en este tipo de políticas, el acuerdo, en términos generales, satisfizo sus metas ya que se logró una inflación decreciente y la eliminación de las restricciones cambiarias.

Giraldo (2000, p.8) expresó que con la eliminación de las restricciones cambiarias, el control de variables macroeconómicas se le cedió al mercado privado de capitales, lo que resulta pe-

\footnotetext{
${ }^{13}$ En el Acuerdo de 2002 se propuso el incremento del impuesto a las transacciones financieras de 0,3\% a 0,4\%.
} 
ligroso, puesto que los inversionistas privados "asumen riesgos excesivos con la esperanza de ser sacados de apuros financieros mediante la intervención oficial". Esto sucedió durante la crisis de 1999 con la creación del dos por mil, que generó desestímulos y pérdida de credibilidad en el Estado por parte de los colombianos pobres, ya que las acciones del Estado mostraron preferencia a favor de los capitalistas del país, por lo que la credibilidad de sus políticas económicas quedaría debilitada, con el consecuente aumento de la incertidumbre de los menos favorecidos, evidenciado en por qué sí surgió un impuesto para rescatar al sistema financiero, pero no un salvamento para que la gente no perdiera sus inmuebles bajo la crisis de la unidad de poder adquisitivo constante UPAC.

\section{Política fiscal y reformas estructurales}

Una de las preocupaciones, en cada acuerdo, era proporcionarle estabilidad a las Finanzas Públicas. Los gobiernos de Pastrana y Uribe orientaron sus esfuerzos a reducir el déficit de estas, ampliando la reforma laboral para aumentar la flexibilidad del mercado laboral (Moncayo \& Rojas, 1978), así como reformas tributarias y privatizaciones. Sobre el mercado laboral, el Acuerdo (2002) expresó:

El gobierno ha presentado revisiones de la ley laboral al Congreso con el objeto de fomentar la expansión del empleo. Esta propuesta debería reducir los costos laborales mediante la prolongación de la jornada diaria de trabajo, y la reducción de costos por concepto de pago de horas extras e indemnizaciones por despido (p.10).

\section{Esta medida se apoyó en el numeral 17 del Acuerdo (2002):}

En septiembre de 2002 el gobierno presentó (...) el borrador de propuesta que (...) aumentaría la edad de retiro a 58 y 62 años para mujeres y hombres respectivamente en el año 2009 , y a 62 y 65 años en 2018. Adicionalmente, el período de contribución se aumentaría (...) de 1.000 a 1.300 semanas en 2018 (p.7).

No obstante, el FMI señaló que las rigideces existentes en el mercado laboral han ayudado al alto nivel de desempleo del país. Estos esfuerzos se tradujeron en despidos masivos de trabajadores estatales, reducción de beneficios sociales, reducción de las transferencias a las regiones, disminución de los salarios y mayores impuestos a la población (Giraldo, 2000). 
En cuanto a las reformas tributarias, en el numeral 16 del Acuerdo (2002), se señala que las principales medidas fiscales contempladas en el programa son:

[Elevar] la tasa general del IVA de 10 por ciento, aplicable a algunos productos, a la tasa general de 16 por ciento; y se expandiría la base de dicho impuesto. Los artículos que serían adicionados a la base, incluyendo algunos comestibles básicos, serían gravados al 5 por ciento (p.6).

En materia de privatizaciones en el Acuerdo (2005) se encuentra que:

El gobierno piensa llevar a punto de venta a Ecogas en 2005. Contratará un banco de inversión para poder llevar varias empresas regionales de electricidad (la Empresa de Energía de Cundinamarca, la Electrificadora del Meta, la Empresa de Energía de Boyacá, la Electrificadora de Santander y la Central Eléctrica del Norte de Santander S. A.) al punto de venta en junio de 2006 (p.8).

El FMI, justificó estas medidas desde la necesidad de realizar ajustes contraccionistas en los campos fiscales y monetarios. Además de la liberalización de todos los mercados, para que se lograra la estabilidad macroeconómica y la mejoría de las condiciones de vida de la población. Sin embargo, para Sarmiento (2005) la liberación comercial ha tenido un efecto totalmente opuesto, porque redujo los precios de la mano de obra no calificada y deprimió el salario de la misma. Asimismo, Carrasquilla (2009) sostiene que la mejor política fiscal es el crecimiento económico, es decir, que un país debe ejercer soberanía en el control de su tasa de tributación, porque de no ejercerla se generaría incertidumbre y zozobra en las personas, lo que incrementaría la pobreza.

Así el FMI, según Sarmiento (2005), cree que la solución a la pobreza se consigue a través del asistencialismo del Estado, es decir, cree que la pobreza "puede ser erradicada sin tocar ni manchar el crecimiento económico" (p.60),. Esto se sustenta en el Acuerdo (2005) al señalar que desde 1991 "Colombia ha desarrollado una extensa red de subsidios que han contribuido a mejorar la calidad de vida de los sectores más vulnerables de la población, pero la pobreza continua siendo elevada” (p.9). Pero si la creencia del FMI fuera cierta, la solución a la pobreza, según Sarmiento (2005), estaría en suprimir del presupuesto que el Estado destina a

Las transferencias regionales, en especial las universidades públicas, las apropiaciones en infraestructura física, los aportes a la vivienda social y el bienestar familiar y el SENA (...) Su eliminación liberaría $\$ 20$ billones y, por simple aritmética, los ingresos de los estratos 1,2 y 3 más que se triplicarían, y la pobreza quedaría en la historia (pp. 59-60). 
Esta medida reduciría el crecimiento potencial de la economía en el tiempo, por lo que quedaría en evidencia que al Fondo no le interesa de manera directa el crecimiento económico y el desarrollo del país, puesto que condiciona el crecimiento y el bienestar de la población. Así, Vargas (2004) señala que como: "los pobres están, la mayoría de las veces, fuera del mercado, [por ende no le interesan] al FMI" (p.14).

En oposición a lo anterior, la superación de la pobreza estaría en la creación de libertades y autonomía de los seres humanos, que les permitan desarrollar fuentes de satisfactores, controladas por ellos mismos, con el fin de que estos puedan administrar y re-crear su propia incertidumbre. En este sentido la incertidumbre debe concebirse como un bien de la persona, algo que le ofrece oportunidades para escapar de su condición de pobreza. Sin embargo, las políticas económicas que recomienda el FMI se orientan, según Gamarra (2003) a ajustar "la demanda agregada independientemente del nivel de oferta agregada (...) [Así], un ajuste (...) resulta en una nivelación de la economía por su punto bajo. Es decir, se reduce el crecimiento potencial de la economía" (p.23),. Por ende, se puede expresar que los acuerdos con el FMI condicionaron la política económica del país, que trajo un problema de credibilidad en el manejo económico del mismo. Gamarra (2003) dice que la credibilidad incide sobre:

Las decisiones intertemporales de los agentes en variables como el consumo, la inversión y el ahorro, y repercute en los agregados económicos, reforzando o neutralizando los objetivos de política, según sea el grado de credibilidad que los agentes tengan de la sostenibilidad de dichas políticas (p.23).

Entonces, la credibilidad de esas políticas se debería reflejar en el cumplimiento de las metas pactadas en el ajuste con el FMI. No obstante, haciendo una evaluación comparativa entre los resultados y las metas pactadas en los acuerdos, expuestos en el cuadro 1, se puede observar que 40 de las 63 metas trazadas no fueron alcanzadas. En materia de crecimiento económico, las metas se vieron sobrepasadas por los resultados en unos años, mientras que en otros no. Frente a las metas fiscales se puede decir que el acuerdo fracasó ya que el crecimiento de la deuda pública del país es evidente, a pesar de que supuestamente el elemento esencial de cada acuerdo era garantizar la sostenibilidad y viabilidad de las finanzas públicas.

También, se puede ver que las reformas estructurales -disminución de las transferencias, aumentos de impuestos, privatizaciones- se llevaron a cabo, con excepción de la Ley Orgá- 
nica del Presupuesto, que pretendían minimizar, en mayor medida, el gasto público. En cuanto las metas monetarias, el acuerdo cumplió medianamente con lo trazado. Respecto de las metas externas, se logró lo que se proponía, ya que se adoptó el régimen de la tasa de cambio libre; el nivel de reservas internacionales aumentó; y la evolución del saldo de la BP fue positiva.

Al revisar las cifras del cuadro 1, se puede afirmar que las políticas económicas, de los gobiernos de Pastrana y de Uribe, carecieron de credibilidad. En consecuencia, se infiere que los acuerdos pretendían reducir el grado de incertidumbre para los inversionistas, que se reflejó en el alcance de las metas en el ámbito externo de la economía colombiana (reducción de la inflación, liberalización de los tipos de cambio, protección de la rentabilidad de los capitales). En cambio, en el escenario interno no se alcanzaron las metas. Muestra de ello está en la retirada del FMI del país sin haber resuelto los problemas de la deuda pública y del déficit fiscal. Finalmente, algunos críticos, como Kolko (1999), han señalado que varios países que aplicaron los ajustes estructurales del FMI

Han experimentado profundas crisis económicas: crecimiento bajo o incluso en declinación, deudas externas mucho más grandes y el estancamiento que perpetúa la pobreza sistémica. [De hecho] algunos estudios del [FMI proporcionan] una evaluación devastadora de las consecuencias económicas y sociales de su asesoramiento en docenas de naciones pobres (p. 53).

Entonces, se concluye que aunque el FMI no tiene en su misión, reducir la pobreza como objetivo central, sí ha tenido la intención de reducirla. No obstante, lo que logra por medio de sus intervenciones es un fortalecimiento del capitalismo -reduciendo casi a cero la incertidumbre para el capital del inversionista-, lo cual se traduce en un aumento y una prolongación de la incertidumbre incontrolable que agobia a los pobres, intensificando su pobreza por la extinción paulatina del flujo de servicios regulares a las cuales podían acceder (tales como servicios públicos, mejores prebendas en materia laboral, menores impuestos, entre otras), pero por los ajustes pactados en los acuerdos su acceso se complicó.

Desde esta perspectiva es posible plantear que las intervenciones del FMI en Colombia, en la medida en que garantizaron la rentabilidad del capital, reafirmaron las condiciones que fundamentan la incertidumbre de los pobres. Situación que se considera invisibilizada por reducciones artificiales -obtenidas de ajustes metodológicos-de los indicadores oficiales de pobreza (Casas, 2015). Sin embargo, como los indicadores externos del país mejoraron el 
FMI asevera que Colombia es menos pobre. No obstante, nótese que no habla de personas pobres. Por ello, la hipótesis del documento queda demostrada ya que por su concepción reduccionista de la pobreza, aunado al hecho de que no diferencia entre país pobre y personas pobres sus intervenciones, difícilmente, resolverán los problemas de las personas pobres; pues su método es de carácter agregado y apunta a encontrar equilibrios entre indicadores generales.

Por ello, se hacen necesarias otras medidas, diferentes al asistencialismo improductivo, tales como brindar más apoyo al desarrollo del capital humano y físico, suscitar el cambio estructural e institucional, devolverles la soberanía y la autonomía a los países, entre otras. Esto, en el papel, lo propone el FMI, a través del proceso de ajuste. No obstante, el inconveniente es que algunas medidas del Fondo, traen inmersas el incumplimiento de los mismos objetivos trazados en los acuerdos, originado por diagnósticos incompletos sobre la realidad situacional de los países donde interviene. Por ejemplo, cuando se privatiza una universidad pública, los habitantes de esa región tendrán menos posibilidades de acceder a la educación, con lo que se afectarían sus posibilidades, su cultura, entre otras características lo que repercutirá en un menor crecimiento, mayor informalidad y más pobreza.

\section{Comentarios Finales}

Después del recorrido de las anteriores líneas se mostró que, en los análisis de la pobreza, la incertidumbre, como un elemento vital para su concepción, estaba ausente; al identificarlo, no se resuelve la pobreza en el mundo, pero lo que se logra es una mejor interpretación del fenómeno de la pobreza. De ahí que se hace necesario que los más afectados por la pobreza, sean escuchados y tenidos en cuenta para la elaboración y diseño de políticas económicas, puesto que estos son las víctimas en el caso de que las políticas fallen. En este sentido, la incertidumbre resulta esencial para la teoría económica, en el marco de reedificar el concepto de pobreza, ya que de seguirse desconociendo este elemento en la composición de la pobreza es factible que los recursos orientados a aminorar los efectos negativos de esta sigan diluyéndose en un asistencialismo improductivo.

Además, es pertinente incluir la incertidumbre a las discusiones de la pobreza, ya que esta se encuentra presente, en la mayoría de ocasiones, situaciones y sensaciones en los seres 
humanos. Así, al igual que a la manera del loco de la mancha, el concepto de incertidumbre ha de buscar su espacio en los molinos de viento de la ciencia económica: un espacio que ha sido sustraído a través del discurso invisible al que se ha hecho referencia por parte del FMI, un espacio político-social que ha de poblarse con las voces y las expresiones de los pobres, para transformar su realidad y que la puedan vivir, desde una concepción que los haga sentir, por fin, que su humanidad se yuxtapone por encima de los resultados económicos.

Finalmente, resulta claro que la incertidumbre incontrolable es impuesta por el sistema capitalista, y es justo lo que los pobres no desean. En este sentido, se hace trascendental revaluar el papel del mismo sistema capitalista, ya que es un sistema que no incluye ni piensa en los pobres. No es que los pobres reclamen siempre estar exentos de incertidumbre, pues ellos también son capaces de resolver en parte sus problemas, siempre y cuando tengan la oportunidad de hacerlo, es decir, que puedan endogeneizar esa incertidumbre para darle un tratamiento de acuerdo a sus preferencias y posibilidades y, en este sentido, la incertidumbre deja de ser una fuente de malestar para convertirse en una motivación de superación y de esperanza en los pobres. En consecuencia, este documento considera que la superación de la pobreza se encuentra, especialmente, en la creación de libertades y autonomía de los seres humanos, que les permitan desarrollar fuentes de satisfactores, controladas por ellos mismos, con el fin de que estos puedan administrar y re-crear su propia incertidumbre.

\section{Referencias}

Acuerdo (1999). Ministerio de Hacienda. Acuerdo extendido de Colombia con el Fondo Monetario Internacional. Santafé de Bogotá D. C., Colombia.

Acuerdo (2002). Ministerio de Hacienda. Acuerdo extendido de Colombia con el Fondo Monetario Internacional. Santafé de Bogotá D. C., Colombia.

Acuerdo (2005). Ministerio de Hacienda. Acuerdo extendido de Colombia con el Fondo Monetario Internacional. Santafé de Bogotá D. C., Colombia.

Beluche, O. (1997). Pobreza y neoliberalismo en Panamá, Recuperado de: http://bdigital. binal.ac.pa/bdp/pobrezayneoliberalismo.pdf. 
Brau, E. (2001). Organización y operaciones financieras del FMI, Recuperado de: http:// www.elibrary.imf.org/view/IMF054/02390-9781589061149/02390-9781589061149/ front.xml?redirect=true

Carrasquilla, A. (2009, 28, Junio). Una fábula y seis moralejas. El Espectador. Recuperado de: http://www.elespectador.com/opinion/una-fabula-y-seis-moralejas-columna-147881.

Casas, J. (2009). El concepto de pobreza y sus implicaciones en Colombia. Revista Apuntes del CENES, 28(47).

Casas, J. (2015). Metodologías de estimación de la línea de pobreza absoluta en Colombia: Una reflexión. Económicas CUC, 36(1), 217-244. doi: http://dx.doi.org/10.17981/econcuc.36.1.2015.28

Clift, J. (2004). ¿Qué es el Fondo Monetario Internacional?, Recuperado de: https://www.imf. org/external/pubs/ft/exrp/what/spa/whats.pdf.

Coudouel, A., Hentschel, J., \& Wodon, Q. (2002). Capítulo 1: Medición y análisis de la pobreza. Banco Mundial, 1.

Elster, J. (1991). Juicios Salomónicos: Las limitaciones de la racionalidad como principio de decisión. Primera edición en español. Editorial Gedisa, Barcelona.

FMI, (2011). Colombia: arrangement under the flexible credit line and cancellation of the current arrangement-staff report; staff supplement; press release on the executive board discussion; and statement by the alternate executive director for Colombia, Recuperado de: http://www.imf.org/external/pubs/ft/scr/2011/cr11162.pdf.

FMI, (2013). Datos básicos, Recuperado de: http://www.imf.org/external/np/exr/facts/spa/ glances.htm.

Gamarra, A. (2003). Evaluación de los acuerdos Colombia FMI 1999-2003. Informe sectorial y de políticas públicas. Informe 4.

Garay, L. J. (1998). Colombia: estructura industrial e internacionalización 1967-1996. Biblioteca virtual del Banco de la República, 563-614. 
Giraldo, C. (2000). El acuerdo con el Fondo Monetario Internacional: un ajuste que llevará la economía al colapso, Recuperado de: http://cedetrabajo.org/wp-content/ uploads/2012/08/27-10.pdf.

Giraldo, C. (2001). Acuerdo de Colombia con el Fondo Monetario Internacional, Recuperado de: https://www.gestiopolis.com/acuerdo-colombia-fondo-monetario-internacional-1999/.

Keynes, J. M. (2014). Teoría general de la ocupación, el interés y el dinero. Fondo de cultura económica.

Kolko, G. (1999). Ravaging the poor: the International Monetary Fund indicted by its own data. International Journal of Health Services, 29(1), 51-57.

Marx, K. (1975). El capital: crítica de la economía política: libro primero. Siglo Veintiuno.

Misas, G. (2002). La ruptura de los 90 del gradualismo al colapso. Univ. Nacional de Colombia.

Moncayo, V. M., \& Rojas, F. (1978). Luchas obreras y politica laboral en Colombia. La carreta.

Ocampo, J. A., Bajraj, R., \& Martin, J. (2001). Una década de luces y sombras: América Latina y el Caribe en los años noventa. Alfaomega.

Pindyck, R. \& Rubinfeld, D. (2009). Microeconomía. Séptima Edición. Editorial: PrenticeHall.

Robledo, J. (2007). Un Balance Desastroso, Recuperado de: http://www.neoliberalismo.com. co.

Sachs, J. (2013). El fin de la pobreza: cómo conseguirlo en nuestro tiempo. Debate.

Sarmiento, E. (2005). Políticas estructurales contra la pobreza, Recuperado de: http://www. contraloriagen.gov.co/html/RevistaEC/pdfs/310_3_5_Politicas_estructurales_contra_ la_pobreza.pdf.

Vargas, M. (2004). Pobreza, mercado y ciudadanía. Revista Iztapalapa, 57, 169-188.

Stiglitz, J. (2009, 13, Junio). Socialismo para los ricos. El Espectador. Recuperado de: http://www.elespectador.com/opinion/columnistasdelimpreso/joseph-e-stiglitz/columna145697-socialismo-los-ricos. 